\title{
Fuzzy Index and Self-Organizing Feature Map Index for Measuring Functional Diversity Applied to Acanthopanax Senticosus Communities
}

\author{
Naiqi Song ${ }^{1}$, Jintun Zhang ${ }^{2, *}$ and Xin Wang ${ }^{2}$ \\ ${ }^{1}$ School of Chinese Materia Medica, Beijing University of Chinese Medicine, Beijing 100102, China \\ ${ }^{2}$ College of Life Sciences, Beijing Normal University, Beijing 100875, China \\ *Corresponding author
}

\begin{abstract}
Methods for measuring functional diversity are the basis of community studies. Two newly functional diversity indices, fuzzy index and SOFM index, were applied and tested in functional diversity analysis in Acanthopanax senticosus communities in the Dongling Mountains in China. Thirty quadrats were established in Acanthopanax senticosus communities and species composition, traits and environmental variables were measured and recorded. Eleven functional traits were used in the calculation of functional diversity. The results showed that fuzzy index and SOFM index were effective methods in functional diversity studies. Fuzzy index and SOFM index provided similar results to that of other common methods. Functional diversity in Acanthopanax senticosus communities varied obviously; functional diversity was significantly correlated with slope and elevation; functional diversity was positively correlated with species richness, heterogeneity, and negatively correlated with evenness.
\end{abstract}

Keywords-unctional trait; iversity; antitative method; ant community; lant conservation

\section{INTRODUCTION}

Study on functional diversity in plant communities has become a hotspot in ecology in recent years, because it is important for community structure and development [1]. Functional diversity in communities is a key driver of ecosystem processes, ecosystem resilience to environmental change, and ecosystem services [2, 3]. Functional diversity refers to the change of species functions in communities, and species functions are reflected by functional traits, i.e. functional diversity is a measure of species trait diversity [4]. The differences in types, change amplitude and stability of these functional traits reflect the quantity of functional diversity in community [5]. Quantitative methods for measuring functional diversity based on species traits have attracted much attention, and many studies tried to develop methodology in this area $[6,7]$. The fuzzy mathematical method (fuzzy equivalence clustering index, fuzzy index) [8] and the artificial neural network method (self-organizing feature map index, SOFM index) [9] were new methods applied to functional diversity analysis. We aimed to apply these two methods to the study of functional diversity of Acanthopanax senticosus communities in the Dongling Mountains in China and to test their effectiveness.

Acanthopanax senticosus (Rupret Mzxim) Harms is a deciduous shrub species in the genus acanthopanax of
Araliaceae family, and mainly distributes in North China and far Eastern Russia, and North Korea, Japan also have some distribution. Acanthopanax root bark, stem bark, leaves, flowers and fruits can be used as medicine, replenishing to invigorate the spleen and kidney, soothing, and its beneficial effect on strong bones comparable with ginseng [10]. In recent years, the industrial exploitation increased the consumption of Acanthopanax senticosus greatly, compounded by human interference and deforestation, and its wild resources declined sharply. It was included in "The directory of protected rare and endangered plants in China" published in 1987. As Chinese traditional medicinal plant, the exploration and utilization of Acanthopanax senticosus has been practiced for thousands of years, but its further research is neglected. Currently studies mainly focus on its medicinal properties, chemical composition and breeding, but the studies on its community ecology, endangering mechanisms, diversity was insufficient. This work also aimed to study the relationships between functional diversity and environmental variables in Acanthopanax senticosus communities.

\section{MATERIAL AND METHODS}

\section{A Data Collection}

The Dongling Mountain is located at $40^{\circ} 00^{\prime}-40^{\circ} 05^{\prime} \mathrm{N}$, $115^{\circ} 26^{\prime}-115^{\circ} 40^{\prime} \mathrm{E}$, and is an extension of the Xiaowutai Mountains and belongs to the broader Taihang Mountain range in Beijing, China. It has a typical warm temperate continental monsoon climate with average annual precipitation of $500-650 \mathrm{~mm}$. The annual mean temperature is $7^{\circ} \mathrm{C}$, the monthly mean temperatures of January and July are $-7.8^{\circ} \mathrm{C}$ and $21.1^{\circ} \mathrm{C}$ respectively. Several soil types, such as cinnamon soil, mountain cinnamon soil, brown forest soil and mountain meadow soil can be found in this mountain [11]. The elevation varies from $800 \mathrm{~m}$ to $2301 \mathrm{~m}$. Vegetation mainly includes secondary forests, scrublands from 800 to $1600 \mathrm{~m}$, and mountain meadows from 1600 to the mountain submit. Acanthopanax senticosus is survival in secondary forests in this area. 
TABLE I. PLANT FUNCTIONAL TRAITS AND THEIR VALUES IN ACANTHOPANAX SENTICOSUS COMMUNITIES IN THE DONGLING MOUNTAINS IN CHINA

Functional trait type

Functional traits and values

$\begin{array}{ll}\begin{array}{l}\text { Photosynthesis } \\ \text { pathway }\end{array} & \begin{array}{l}1 \text { Crassulacean pathway, 2 C3 pathway, 3 } \\ \text { between C3 and C4 pathway, 4 C4 pathway }\end{array} \\ \text { Nitrogen-fixing } & \begin{array}{l}0 \text { No nitrogen-fixing, 1 Elaeagnaceae } \\ \text { nitrogen-fixing, 2 Leguminosae nitrogen-fixing }\end{array} \\ \text { Seed dispersal } & \begin{array}{l}1 \text { Automatic spreading, 2 gravity spreading, 3 } \\ \text { wind spreading, 4 animals spreading }\end{array} \\ \text { Pollination method } & \begin{array}{l}1 \text { Anemophilous, 2 entomophilous } \\ \text { Life cycle }\end{array} \\ \text { Life-form } & \begin{array}{l}1 \text { Annual, 2 biennial, 3 perennial } \\ \text { herb, } 5 \text { annual herb }\end{array} \\ \text { Leaf form } & \begin{array}{l}1 \text { Coniferous, 2 Broad leaf } \\ \text { Plant height }\end{array} \\ \text { Plant cover } & \begin{array}{l}\text { Measured value in cm } \\ \text { Flowering date }\end{array} \\ \text { Flowering period } & \begin{array}{l}\text { Beginning month of flowering } \\ \text { Flowering months }\end{array}\end{array}$

According to the distribution of Acanthopanax senticosus and to the variation of elevation, aspect and slope, 30 typical quadrats of Acanthopanax senticosus communities were set up in Dongling Mountains. The quadrat size was $10 \mathrm{~m} \times 10 \mathrm{~m}$. Species name, cover, height, basal area and individual abundance for tree species and name, cover and height for shrubs and herbs were measured and recorded in each quadrat [12]. The plant height was measured by using a height-meter for trees and a steel-tape ruler for shrubs and herbs. The basal diameter of trees was measured by using a caliper and was used to calculate the basal area. A total of 125 plant species were recorded in 30 quadrats. Elevation, slope, aspect, and litter thickness for each quadrat were also recorded. The elevation was measured by using a GPS, the slope and aspect were measured by using a compass meter and the litter thickness was measured by using a ruler directly [12]. The elevation, slope and litter thickness were reading values, while the aspect measurements were classified from 1 to 8 in the following way: $1 \quad\left(337.6^{\circ}-22.5^{\circ}\right), 2 \quad\left(22.6^{\circ}-67.5^{\circ}\right), \quad 3$ $\left(292.6^{\circ}-337.5^{\circ}\right), \quad 4 \quad\left(67.6^{\circ}-112.5^{\circ}\right), \quad 5 \quad\left(247.6^{\circ}-292.5^{\circ}\right), 6$ $\left(112.6^{\circ}-157.5^{\circ}\right), 7\left(202.6^{\circ}-247.5^{\circ}\right)$, and $8\left(157.6^{\circ}-202.5^{\circ}\right)$.

Eleven functional traits were selected to illustrate plant species function in community (Table 1). Photosynthesis pathway, seed dispersal, pollination manner and nitrogen-fixing were identified from local flora and life-form, leaf form, plant height, plant cover, flowering date, flowering period and life cycle were observed and measured in field. To calculate functional diversity, a data matrix of functional traits $\times$ species in a quadrat was constructed, and totally there were 30 data matrices for 30 quadrats.

\section{B Data Analysis}

\section{1) Fuzzy index}

Fuzzy equivalence clustering index (fuzzy index) is a dendrogram index which clusters species into a dendrogram based on fuzzy equivalence relations calculated from a matrix of functional traits, and then used the sum of branch lengths of the dendrogram as a multivariate measure of functional diversity [8]. Firstly, we calculated fuzzy relationship matrix $(\mathrm{R}=[\mathrm{rjk}])$ between species $[12,13]$. We use the follow formula:

$$
r_{j k}=\frac{\sum_{i=1}^{N} x_{i j} x_{i k}}{\sqrt{\sum_{i=1}^{N} x_{i j}^{2} \sum_{i=1}^{N} x_{i k}^{2}}}
$$

where rjk is the fuzzy similarity between species $\mathrm{j}$ and $\mathrm{k}$; $\mathrm{xij}$ and xik are values of trait $i$ for species $j$ and $k$ respectively.

Secondly, Transforming fuzzy relationship matrix $\mathrm{R}$ into fuzzy equivalence relation matrix $\left(\mathrm{R}^{*}\right)$. Thirdly, Clustering species based on fuzzy equivalence relations $\mathrm{R}^{*}$. The result provides a hierarchical system and a corresponding dendrogram [9]. Fourthly, Adding the lengths of dendrogram branches to get fuzzy functional diversity index.

\section{2) SOFM index}

SOFM neural network consists of two layers, input layer and output layer. The input layer contains a unit (neuron) for each variable (species functional trait) in the data set. The input units operate in a similar way to those in other neural networks, effectively presenting the data for each species to the network in an appropriate format. The input units are connected directly to units in the output layer. The output layer is also a two-dimensional array of units and each of these units is connected to every unit in the input layer by a weighted connection [14].

Through initializing, we gave initial values of Wij within $[0,1]$ randomly $(i=1,2, \ldots, N ; j=1,2, \ldots, M)$, initial values of learning rate $\eta(0)$ and neighborhood $\mathrm{Ng}(0)$, and determined total learning times $\mathrm{T}$. The parameterization of the SOFM used was that the learning rate was 0.1 for the ordinating phase and 0.02 for adjusting phase; the learning phase was broken down into 5000 steps for the ordinating phase and 50000 steps for the tuning phase. When the learning process is finished, a topological map of small squares is obtained and species units can be mapped into the corresponding squares. This map reflects the distribution of species in functional trait space. And then calculating functional distances between species and SOFM functional diversity [12],

$$
d_{j k}=\sqrt{\left(x_{j}-x_{k}\right)^{2}+\left(y_{j}-y_{k}\right)^{2}}
$$




$$
S O F M_{F D}=\frac{1}{2} \sum d_{j k}
$$

$$
(\mathrm{j}=\mathrm{k}=1,2, \ldots, \mathrm{S}=\text { species number in a quadrat) }
$$

Where djk is functional distance between species $\mathrm{j}$ and $\mathrm{k}$ in topological space, $\mathrm{xj}$ and $\mathrm{xk}$ are scores of species $\mathrm{j}$ and $\mathrm{k}$ on $\mathrm{x}$ axis, and yj and yk are scores of species $\mathrm{j}$ and $\mathrm{k}$ on $\mathrm{y}$ axis.

\section{3) Compared Methods}

To test the effects of fuzzy index and SOFM index, three common methods were applied and their results were compared.

\section{4) Functional attribute diversity (FAD)}

FAD aimed at estimating the dispersion of species in trait space as the sum of the pairwise species distances [15]:

$$
F A D=\sum_{i, j} d_{i j}
$$

Where dij is functional distance between species $\mathrm{i}$ and $\mathrm{j}$ in functional trait space; $\mathrm{D}=\{\mathrm{dij}\}$ is Euclidean distance matrix and calculated based on the matrix of functional traits $(\mathrm{N})$ by species (S).

TABLE II. FUNCTIONAL DIVERSITY VALUES IN DIFFERENT QUADRATS IN ACANTHOPANAX SENTICOSUS COMMUNITIES IN THE DONGLING MOUNTAINS IN CHINA

\begin{tabular}{ccc||ccc}
\hline Quadrat & $\begin{array}{c}\text { Fuzzy } \\
\text { index }\end{array}$ & $\begin{array}{c}\text { SOFM } \\
\text { index }\end{array}$ & Quadrat & $\begin{array}{c}\text { Fuzzy } \\
\text { index }\end{array}$ & $\begin{array}{c}\text { SOFM } \\
\text { index }\end{array}$ \\
\hline 1 & 2.78 & 159.2 & 16 & 2.62 & 170.2 \\
2 & 2.87 & 169.3 & 17 & 3.22 & 201.0 \\
3 & 1.99 & 117.6 & 18 & 1.98 & 116.5 \\
4 & 1.62 & 86.2 & 19 & 3.02 & 180.3 \\
5 & 2.02 & 148.3 & 20 & 1.89 & 107.4 \\
6 & 2.03 & 133.7 & 21 & 2.28 & 166.7 \\
7 & 2.00 & 129.2 & 22 & 2.01 & 120.3 \\
8 & 2.75 & 164.8 & 23 & 1.65 & 89.7 \\
9 & 1.79 & 103.5 & 24 & 1.73 & 98.9 \\
10 & 2.09 & 143.5 & 25 & 1.59 & 67.8 \\
11 & 1.62 & 78.1 & 26 & 1.60 & 73.2 \\
12 & 1.78 & 102.4 & 27 & 1.78 & 108.1 \\
13 & 2.23 & 139.2 & 28 & 2.33 & 138.6 \\
14 & 3.27 & 196.2 & 29 & 3.50 & 199.8 \\
15 & 2.30 & 176.8 & 30 & 3.42 & 202.2 \\
\hline
\end{tabular}

5) Plot-based functional diversity

This functional diversity index is based on functional dendrogram and is the total branch length of the functional dendrogram that can be constructed from information about species functional traits (Petchey and Gaston 2006). Plot-based Functional diversity (FDp) is plot based index which recalculate the dendrogram for each quadrat, but in doing so the desirable property of 'set monotonicity' does not hold.

\section{6) Community-based functional diversity}

This index is also the total branch length of the functional dendrogram, but community-based functional diversity (FDc) corrected the lack of monotonicity that arises when there is a particular dendrogram for each quadrat.

\section{7) Species diversity}

Three species diversity indices, one for species richness (species number S), one for species heterogeneity (Shannon-Wiener index H'), and one for species evenness (Pielou index E), were used to calculate species diversity values $[12,16]$.
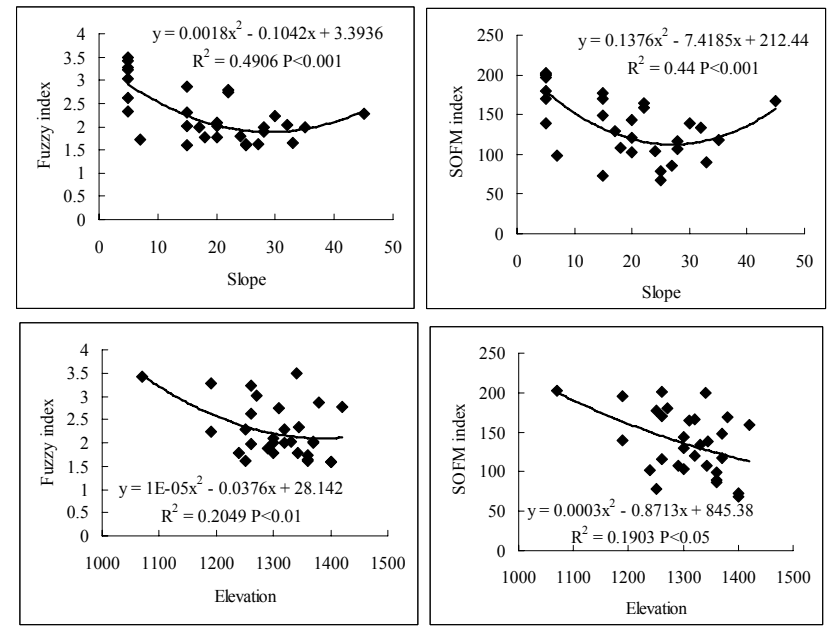

FIGURE I. REGRESSION ANALYSIS OF FUZZY INDEX AND SOFM INDEX WITH ENVIRONMENTAL VARIABLES IN ACANTHOPANAX SENTICOSUS COMMUNITIES IN THE DONGLING MOUNTAINS IN CHINA

\section{RESULTS}

The fuzzy index and SOFM index were calculated by using the fuzzy mathematical toolbox and the neural network toolbox in MATLAB respectively. Other functional diversity indices, namely FAD, FDp, FDc, were calculated with the FDiversity software (Casanoves et al., 2011). Functional diversity indices varied greatly in Acanthopanax senticosus communities in the Dongling Mountains (Table 2). The fuzzy index varied from 1.59 to 3.50 , SOFM from 67.8 to 202.2 , FAD from 33.09 to 220.28 , FDp from 4.3 to 9.13 , and FDc from 4.34 to 9.15 . These indices showed that functional diversity was comparatively rich in Acanthopanax senticosus communities compared to that in other forests in this area $[1$, $13]$. 

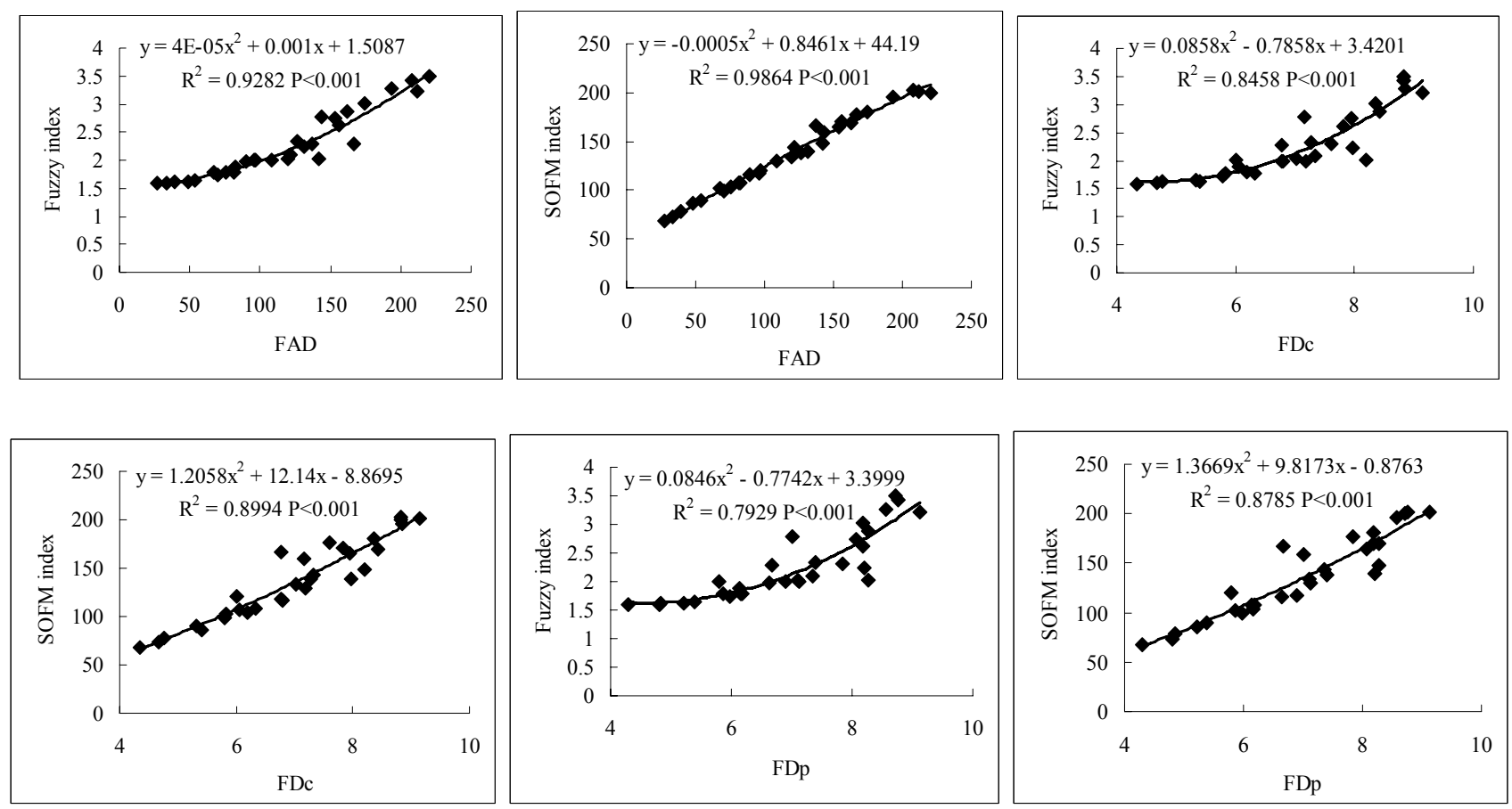

FIGURE II. REGRESSION ANALYSIS OF FUZZY INDEX AND SOFM INDEX WITH OTHER THREE FUNCTIONAL DIVERSITY INDICES IN ACANTHOPANAX SENTICOSUS COMMUNITIES IN THE DONGLING MOUNTAINS IN CHINA. FAD, FDP AND FDC REFER TO FUNCTIONAL ATTRIBUTE DIVERSITY, PLOT BASED FUNCTIONAL DIVERSITY AND COMMUNITY BASED FUNCTIONAL DIVERSITY RESPECTIVELY

The variability of functional diversity was dependent on the variation of environmental variables $[12,17]$. Fuzzy index and SOFM index were significantly correlated with elevation and slope (Fig. 1), but their correlations with aspect and litter thickness were not significant. Other indices showed similar correlations with these variables. Functional diversity showed a non-linear correlation with elevation and slope. Elevation and slope were the most important factors affecting functional diversity in Acanthopanax senticosus communities. All the indices showed the same pattern with environmental variables which showed that fuzzy index and SOFM index were successful in describing functional diversity and their relations with environmental variables $[11,13]$.

As new methods, fuzzy index and SOFM index could complete functional diversity analysis and provide reasonable results, i.e. describing the functional diversity and its change in Acanthopanax senticosus communities. Furthermore, fuzzy index and SOFM index were significantly and positively correlated with other three common methods (Fig. 2). This suggested that fuzzy index and SOFM index are effective techniques in studies of functional diversity in plant communities [18]. Fuzzy index and SOFM index were significantly and positively correlated with each other (Fig. 3). All the relationships between functional diversity indices were non-linear.

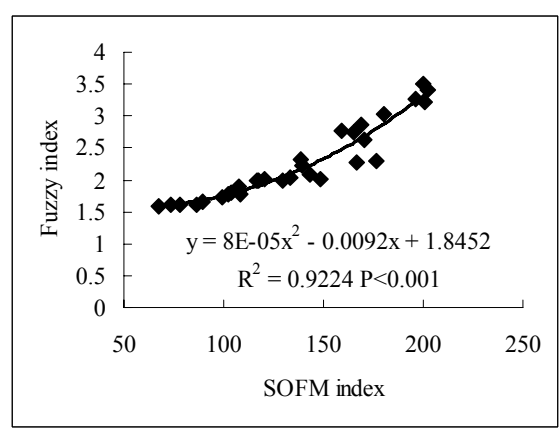

FIGURE III. REGRESSION ANALYSIS BETWEEN FUZZY INDEX AND SOFM INDEX IN ACANTHOPANAX SENTICOSUS COMMUNITIES IN THE DONGLING MOUNTAINS IN CHINA

Functional diversity measured by fuzzy index and SOFM index was significantly related to species richness, diversity and evenness (Fig. 4). Their relations with species richness and diversity were positive, but that with evenness were negative. This was also similar to other common indices [11].

\section{DISCUSSION}

Fuzzy index and SOFM index were successful in describing the quantity and change of functional diversities of Acanthopanax senticosus communities in the Dongling Mountains which suggested that they can perfectly complete the evaluation of functional diversity and are fully usable in plant ecology [8, 12]. Fuzzy index is based on fuzzy 
mathematical theory and SOFM index is based on neural network theory, they are proved useful and have some advantages in plenty of applications including in plant ecology [19]. Theoretically, they should be good methods in evaluation of functional diversity in plant communities [8, 20]. Fuzzy mathematics and neural networks have advantages in solving non-linear problem and in studying complicated and fuzzy systems $[21,22]$. Vegetation ecosystem is a complexity system with various non-linear and fuzzy relations of species, communities and environmental factors [10, 15]. Significant and positive correlations of fuzzy index and SOFM index with the three common methods, FAD, FDc and FDp indices, also proved that these two new indices are effective in quantifying functional diversity in plant communities [16, 23]. The relationships of fuzzy index and SOFM index with other three common indices were all non-linear which showed that they were similar but their effectiveness was different [24, 25].
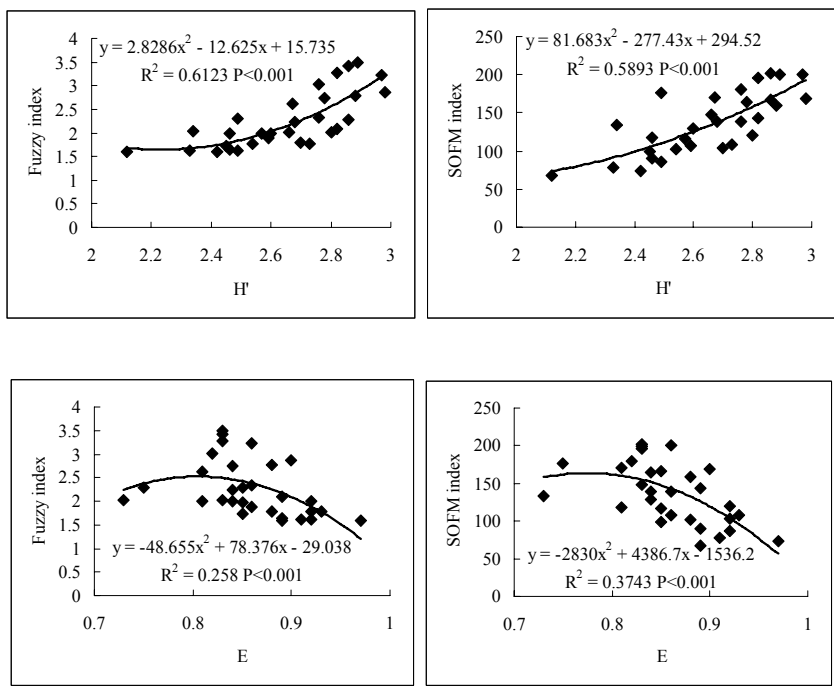

FIGURE IV. REGRESSION ANALYSIS OF FUZZY INDEX AND SOFM INDEX WITH SPECIES DIVERSITY IN ACANTHOPANAX SENTICOSUS COMMUNITIES IN THE DONGLING MOUNTAINS IN CHINA. S, H" AND E REFER TO SPECIES RICHNESS, DIVERSITY AND EVENNESS RESPECTIVELY.

Functional diversity measured by fuzzy index and SOFM index was closely related to slope and elevation, which was consistent with the conclusion that slope and elevation were the key environmental variables affecting community structure, diversity and distribution of Acanthopanax senticosus communities in this mountain reserve [27]. The variations of slope and elevation may lead to the changes of water and heat conditions, soil structure, soil type etc. which affect plant and community growth and development $[15,23]$. The effects of aspect and litter thickness on functional diversity were not significant because Acanthopanax senticosus lived in forest under canopy where litters and aspect were consistent $[11,28]$.

Functional diversity measured by fuzzy index and SOFM index was significantly correlated with species richness, diversity and evenness in Acanthopanax senticosus communities in the Dongling Mountains. This suggested that functional diversity and species richness were interrelated with each other $[25,28]$. Each species should have some special functional traits, therefore the greater the number of species in a community is, the greater the change of functional traits and the greater the functional diversity are [6]. The non-linear relationships between functional diversity and species richness proved that functional diversity and species diversity can not be replaced with each other (Zhang et al. 2012b; 2013). Species diversity can mainly explain the variation of species abundance and distribution, but functional diversity can explain variations of species morphology, physiology, reproduction, ecology and phenology [11, 18, 29]. Fuzzy index and SOFM index provided fully ecological meaningful results which further proved that they were effective in functional diversity analysis in plant communities [23].

\section{ACKNOWLEDGMENTS}

The study was financially supported by the Specialized Research Fund for the Doctoral Program of Higher Education (Grant No. 20120003110024) and the National Natural Science Foundation of China (Grant No. 31170494).

\section{REFERENCES}

[1] J-T. Zhang, N.Q. Song, L.H. Fan. Evaluation of nine distance-based measures of functional diversity applied to forest communities. Annals of Forest Research, 2013, 56(1): 43-52

[2] S. Diaz, S. Lavorel, F. de Bello, F. Que' tier, K. Grigulis, and T. M. Robson. Incorporating plant functional diversity effects in ecosystem service assessments. Proc. Nat. Acad. Sci. (USA), 2007, 104:20684-20689.

[3] E. Laliberte, D.A. Norton, D. Scott. Contrasting effects of productivity and disturbance on plant functional diversity at local and metacommunity scales. Journal of Vegetation Science, 2013, 24: $834-842$

[4] H. Hillebrand, B. Matthiessen. Biodiversity in a complex world: consolidation and progress in functional biodiversity research. Ecology Letters, 2009, 12: 1405-1419

[5] J.-T. Zhang, L.H. Fan and M. Li. Functional diversity in plant communities: Theory and analysis methods. African J. Biotech. 2012a, 11: 1014-1022

[6] Suding, K., Lavorel, S., CHAPIN III, F., et al. (2008). Scaling environmental change through the community-level: a trait-based response-and-effect framework for plants. Glob. Change Biol. 14(5): 1125-1140.

[7] J. Podani, C. Ricotta, J.G. Pausas and D. Schmera. Combinatorial functional diversity: an information theoretical approach. Community Ecology, 2013, 14(2): 180-188.

[8] J-T. Zhang, N.Q. Song, M. Li. Application of Fuzzy Equivalence Clustering to the Analysis of Functional Diversity in Plant Communities. Proceedings of 2012 9th International Conference on Fuzzy Systems and Knowledge Discovery, IEEE \& CAS, 2012b, Vol. 2: 556-560

[9] N.Q. Song, J-T. Zhang. An index for measuring functional diversity in plant communities based on neural network theory. Journal of Applied Mathematics, 2013, Volume 2013, Article ID 320905, 6 pages.

[10] Y. Xu, J.-T .Zhang, Quantitative analysis of endangered Acanthopanax senticosus communities in Dongling Mountain of Beijing. Front. Biol. China, 2008, 3(4): 507-511

[11] Y.Z. Huo. Beijing physical geography. Beijing: Beijing Normal University Press , 1989.

[12] J-T. Zhang. Quantitative ecology (2nd edition), Beijing: Science Press, 2011. (In Chinese)

[13] A. Kaufmann. Introduction to the theory of fuzzy subsets: Vol. 1: foundamental theoretical elements. Academic Press, London, 1975.

[14] J. Lepš, F. de Bello, S. Lavorel and S. Berman. Quantifying and interpreting functional diversity of natural communities: practical considerations matter. Preslia , 2006, 78: 481-501. 
[15] B.H. Walker, A. Kinzig, , J.L. Langridge. Plant attribute diversity, resilience, and ecosystem function: the nature and significance of dominant andminor species. Ecosystems, 1999, 2: 95-113.

[16] E. C. Pielou. Ecological diversity. London: Wiley \& Sons, 1975.

[17] S. Pavoine, M.B. Bonsall. Measuring biodiversity to explain community assembly: a unified approach. Biol. Rev., 2011, 86: 792-812

[18] N. Mason, D. Mouillot, W. Lee, et al. Functional richness, functional evenness and functional divergence: the primary components of functional diversity. Oikos, 2005, 111(1): 112-118.

[19] J.-T. Zhang, S. Li, and M. Li. A comparison of Self-Organizing Feature Map clustering with TWINSPAN and fuzzy C-means clustering in the analysis of woodland communities in the Guancen Mts, China. Community Ecology, 2010, 11: 120-126

[20] O. Petchey, and K.Gaston. Functional diversity: back to basics and looking forward. Ecol. Lett. 2006, 9(6): 741-758.

[21] R. Schalkoff. Pattern Recognition: Statistical Structural and Neural Approaches. Wiley, New York, 1992..

[22] S. Lekand, J.F. Guégan. Artificial Neuronal Networks application to ecology and evolution. Springer, Berlin, pp262, 2000.

[23] E. Laliberte, P. Legendre. A distance-based framework for measuring functional diversity from multiple traits. Ecology, 2010, 91: 299-305

[24] F. de Bello. The quest for trait convergence and divergence in community assembly: are null-models the magic wand? Global Ecology and Biogeography, 2012, 21:312-317

[25] F. Casanoves, L. Pla,, J. Di Rienzo, S. Diaz. FDiversity: a software package for the integrated analysis of functional diversity. Meth. Ecol. Evol. 2011,.2: 233-237

[26] D. Ackerly and W. Cornwell. A trait-based approach to community assembly: partitioning of species trait values into within-and among-community components. Ecol. Lett. 2007, 10(2): 135-145.

[27] J.L. Giraudel and S. Lek A comparison of self-organizing map algorithm and some conventional statistical methods for ecological community ordination. Ecological Modelling, 2001, 146:329-339.

[28] A.D. Papanikolaou, N.M. Fyllas, A.D. Mazaris, P.G. Dimitrakopoulos, A.S. Kallimanis, J.D. Pantis. Grazing effects on plant functional group diversity in Mediterranean shrublands. Biodiver. Conserv. 2011, 20: 2831-2843 